\title{
“¿La poesía es un arma de futuro cargada?” Los compromisos poéticos posmodernos o el canon bajo sospecha
}

\author{
"Is poetry a weapon loaded with future?" The postmodern \\ poetic engagements or the canon under suspicion
}

\author{
ARACELI IRAVEDRA \\ Universidad de Oviedo, Espańa \\ Correo electrónico: airavedra@uniovi.es
}

El canon del compromiso poético español del siglo XX está siendo sometido a un riguroso cuestionamiento por aquellos autores que se postulan hoy como sus continuadores naturales: un hecho que encuentra explicación en el desgaste sufrido por los modelos mediatos, pero también en el nuevo escenario político y en el desfondamiento ideológico de los tiempos. Atender a los nuevos planteamientos del compromiso poético posmoderno en sus principales formalizaciones conducirá a identificar las zonas más revisitadas, aceptadas o impugnadas del canon asentado, y a conocer el volumen de la deuda que aquellos están dispuestos a asumir respecto de sus patrones canónicos.

Palabras clave: poesía, compromiso, posmodernidad, canon

The Spanish canon of twentieth-century poetic engagement is being seriously questioned by those authors who are nowadays considered their natural successors: a fact which finds explanation in deterioration suffered by the mediate poetic models, but also in the new political scene and in the ideological weakening of the times. Examine the new approaches of postmodern poetic engagement in its main formalisations will help to identify the most revisited, accepted or contested areas of the settled canon, and to reveal to what extend those forms feel inheritors of its canonical patterns.

Key words: poetry, engagement, postmodernism, canon 
El canon, como han sostenido no pocos estudios que han salido al paso de las controvertidas tesis de Bloom (1994), mucho antes que una instancia cerrada a partir de intemporales criterios estéticos que garantizan su estabilidad, es una construcción movediza y dinámica, "una lectura intencional del pasado" (Mainer 1998: 274) que no cabe pensar como no ideológica ni como una verdad esencial e inmutable, sino como un proceso colectivo e histórico. De hecho, la Historia ha venido a demostrar que la significación de los textos que entran y salen del canon, construido a cada paso de acuerdo con unos intereses socioculturales no menos que estéticos, y la interpretación a la que son sometidas las obras canónicas, depende antes que de unos valores supuestamente universales, de los contextos de lectura y de la condición de sus lectores, que no necesariamente aceptan su validez indiscutida "como algo cuya consistencia viene avalada por la fuerza de la tradición" (Talens 2000: 362). No en vano, y como de otro modo postulara Borges, cada escritor crea a sus precursores.

Tal cosa resulta paradigmáticamente confirmada por las modulaciones apreciables en las formas de leer el canon del compromiso poético del siglo XX en los últimos años de dicha centuria y los comienzos de la presente, tanto por los historiadores y críticos de la literatura como, sobre todo, por aquellos autores que se postulan hoy como continuadores naturales de ese canon selectivo de la poesía española. Si en otro lugar me he referido a las revisiones de los primeros (Iravedra 2013), quisiera ahora detener la reflexión en las relecturas de los segundos, lo que conducirá a identificar las zonas más revisitadas, aceptadas o impugnadas del canon asentado y, en último término, a conocer el volumen de la deuda que tales autores están dispuestos a asumir respecto de sus patrones canónicos. En este sentido, cabe adelantar que, si algo puede vislumbrarse a la luz de la mayoría de las posiciones sostenidas, es la generalizada reticencia hacia las formas de expresión de la conciencia cívica habilitadas en nuestro pasado reciente por la llamada poesía social, que pasa por ser, como principal materialización española de lo que se denominó realismo socialista, piedra angular de nuestro canon del compromiso. Ello invita sin duda a suscribir, al menos en líneas generales, esta consideración de Leopoldo Sánchez Torre:

Llama [...] la atención la presteza y hasta la vehemencia con que la mayor parte de los nuevos poetas comprometidos tratan de desvincularse de las formas de entender el compromiso durante la posguerra (se admite, como mucho, un parentesco -y lejano- con algunas de las hoy más respetadas: Otero, Hierro y los poetas críticos de los cincuenta). En actitudes y en concreciones discursivas, el compromiso de nuestros días es [...] distinto de su antecedente mediato, pero comparte con él más principios de los que los propios poetas están dispuestos a admitir (2002: 49).

La esclerosis retórica y el formalismo temático a que condujo la reiteración epigonal del modelo pueden en parte explicar el unánime afán de desmarcarse de esta que fue tendencia hegemónica durante los años cincuenta y sesenta del pasado siglo y con la que, en efecto, nadie parece querer alinearse con independencia de la herencia recibida. Basta pensar 
en la distancia sugerida por algunos sintomáticos marbetes con los que los propios autores han bautizado una serie de recetas convergentes en su determinación de involucrarse en los debates públicos: la poesía entrometida de Fernando Beltrán -que señala una indiscreta voluntad de merodeo en la conciencia colectiva y, a la vez, el deseo de diferenciarse de una práctica poética que ha tendido a abandonar el territorio del yo-; la poesía practicable de Jorge Riechmann -que pretende acompañar al ser humano en su existencia y resistencia cotidianas, sin por ello ceder a la instrumentalización del lenguaje-; o el realismo singular de Luis García Montero -que, frente a la acostumbrada negación de los argumentos subjetivos, propone escribir la Historia en primera persona-. Pero en la evaluación de sus deudas con los precedentes canónicos merecen consideración diferenciada los distintos poetas y tendencias, que argumentan con variable coherencia y fortuna el supuesto hiato con la praxis cuestionada. Atenderé a quienes más se han empleado en la problematización de este caso.

\section{LA OTRA SENTIMENTALIDAD: DE LA VOZ COLECTIVA A LA ÉPICA SUBJETIVA}

Antes de venir a postular un realismo singular, Luis García Montero (1993b) se había revelado como uno de los principales componentes de la otra sentimentalidad, esa propuesta programática que en la Granada de los primeros ochenta imprimía una vuelta de tuerca a los debates sobre el compromiso lírico. Según ya se ha examinado en otros lugares (Díaz de Castro 2003; Iravedra 2010a: 24-32), el replanteamiento de este asunto se efectuaba a la luz de un tipo de reflexión sobre la literatura, familiarizada con el marxismo althusseriano, que permitía concebirla como una forma -radicalmente histórica- de producción ideológica. Tal era el discurso que sostenía la Teoría e historia de la producción ideológica (1975) de Juan Carlos Rodríguez, animador teórico del proyecto y cuyas dos tesis básicas -la literatura como discurso ideológico, la radical historicidad de la literatura- procuraban un giro decisivo a los modos de pensar las relaciones entre la Historia y la poesía, y nutrían la especulación y la praxis de Javier Egea, Álvaro Salvador y García Montero, por no citar sino al núcleo originario de la escuela. Aceptar la entidad ideológica de la literatura implicaba romper con la antigua paradoja burguesa de lo privado y lo público e invalidaba, en consecuencia, la tradicional dicotomía "pureza versus compromiso": cualquier palabra está comprometida en su raíz con un inconsciente ideológico, luego las relaciones de la literatura con la Historia se hallan por encima de las decisiones del autor. Complementariamente, desmantelar la idea de la poesía como una esencia previa para pensarla como producción histórica conducía a buscar el compromiso en un discurso materialista capaz de indagar en su raíz ideológica y la del sujeto que la enuncia, de desvelar sus razones históricas para intervenir sobre ellas y, en suma, para abrir una brecha en el horizonte ideológico dominante en busca de la forma de decir o producir otra moral.

Los planteamientos puestos en juego por Juan Carlos Rodríguez proporcionaron a la otra sentimentalidad los fundamentos para discutir las distintas expresiones del realismo socialista: valga por ahora decir que las premisas que orientaban su práctica materialista 
chocaban con unos usos poéticos todavía enredados, paradójicamente, en la ideología burguesa de la poesía con la que el nuevo discurso pretendía romper. En cuanto a la clásica poesía social, que, deudora de tal ideología, canalizaba su compromiso de izquierdas mediante la enunciación directa de contenidos políticos, la lógica interna de la otra sentimentalidad establecía que, mucho antes que en el tema del poema, lo político se juega en el modo de plantearlo, puesto que cada discurso produce "su propia experiencia de significación" (Rodríguez 1999: 36). Si por el contrario se trataba de hacer una poesía de indagación y de transformación del yo, no podía bastar el viejo modelo de la poesía comprometida; había que operar sobre el campo de juego de las vivencias concretas una crítica de acento moral, que desplazaba la antigua enunciación de denuncias políticas y la ilusoria aspiración a controlar con tesis programáticas la ideología social.

Así las cosas, los discípulos de Juan Carlos Rodríguez hubieron de forjarse una genealogía distinta, a la vez que efectuaban una relectura de las lecciones ofrecidas por el canon del compromiso a la medida de los propios intereses y las nuevas certezas conquistadas. Así, en Antonio Machado, a quien algunos han considerado el primer maestro del compromiso en la poesía española del siglo XX (Lechner 2004: 112), no habían de buscar el ingrediente épico de Campos de Castilla, sino su revisión del concepto mismo de sentimentalidad-directo inspirador de la etiqueta de los granadinos-, que les ayudaba a comprender el carácter histórico de los sentimientos, producto de unas realidades sociales y de un horizonte ideológico determinado: "Los sentimientos cambian en el curso de la historia, y aún durante la vida individual del hombre. En cuanto resonancias cordiales de los valores en boga, los sentimientos varían cuando estos valores se desdoran, enmohecen o son substituidos por otros" (Machado 1989: 1957). Esta novedosa reflexión atribuida a Juan de Mairena, y la impugnación machadiana de la "fe, un tanto perversa", en "la pura intimidad del sujeto individual” (1989: 1785), promovía de camino una definición social de la subjetividad y desembocaba en la anulación de las fronteras entre individualidad y sentimentalidad colectiva. Fueron las lecciones de esta zona del pensamiento machadiano las que reforzaron unas convicciones que conducían a los poetas sentimentales a impugnar la sacralización de lo público -con la consiguiente proscripción de la intimidad- promovida por el estalinismo ortodoxo; pero también la falsa alternativa de una literatura política cimentada en la idea del poeta como profeta o sujeto elegido, y encarada esta vez desde una individualidad sacralizada: esto es, cualquiera de las formas de perpetuación de la división burguesa entre lo privado y lo público fundada por el pacto social.

En el sujeto temporal e histórico de Antonio Machado hallaron, así pues, García Montero y sus compañeros de aventura el primer gran modelo contemporáneo para la definición de una nueva poesía cívica. Tras él, Rafael Alberti, tal vez el símbolo máximo del compromiso literario en el pasado siglo, constituyó para ellos otro referente central, aunque la renovada noción de compromiso que ponían en juego imponía también una singular relectura de la vasta producción del gaditano. Por descontado, Alberti representaba para aquellos jóvenes educados en el marxismo una bandera y un arquetipo de poeta civil; pero no todos los registros de su poesía política podían resultarles de interés. Y de hecho no 
asienten a la exploración albertiana que dirige los pasos de El poeta en la calle (1931-1935), donde había una obediencia a las tesis del realismo socialista difundidas en el Congreso de Kharkov (1930), según anuncia el célebre lema de Lenin que preside Consignas: "La literatura debe ser una literatura de partido"; ni asienten a la urgente gramática necesaria de la guerra civil, resuelta en el verso épico y el tono de arenga, o a la nueva poesía de combate contra el franquismo recuperada desde el exilio, por ejemplo en las Coplas de Juan Panadero; y aún menos conectan con el canto "bucólico" a la mitología revolucionaria (Soria Olmedo 1991: 13) de La primavera de los pueblos, libro surgido de la experiencia de los viajes albertianos por la Europa del Este y China, y en el que García Montero ha denunciado una desconexión absoluta de la realidad (2006: 78). A cambio, los de la otra sentimentalidad han reivindicado un camino lírico también transitado por Alberti, muy alejado de la eficacia populista de la propaganda, donde la voluntad política no se canaliza a través de los temas, sino de un análisis histórico de la educación sentimental. Puede localizarse en distintos poemas de la colección De un momento a otro. Poesía e historia (19341939) y, muy especialmente, en la serie de textos agrupados como "La familia (poema dramático)"; pues, en efecto, allí las cuentas con la Historia se ajustan a partir del examen de la propia experiencia y de sus reductos más supuestamente privados, de manera que la denuncia estalla en el interior de la elaboración autobiográfica. Así, esta nueva poesía política no trataba ya de distinguir entre poesía e historia, según reza el subtítulo de la colección, sino de "concebir al yo como un producto histórico, como un lenguaje familiar y social a la vez" (Rodríguez 2003: 112). Por ello, los discípulos de Juan Carlos Rodríguez hallaron en este libro un precedente exacto de esa épica subjetiva que ellos mismos intentaban —un modo de escribir poesía política a partir de una interrogación sobre el yo-, y no dejaron de reclamarlo como el primer eslabón de una cadena que tendría su engarce intermedio en el realismo crítico y experiencial de los poetas del cincuenta.

En el canon de la poesía cívica estos fueron, en efecto, los indiscutibles modelos inmediatos de la otra sentimentalidad, completando entre los españoles la genealogía particular del proyecto. En la nueva manera política de la escritura de Gil de Biedma, Ángel González, José Agustín Goytisolo, ciertas zonas de Barral y Valente, o José Manuel Caballero Bonald, asimismo interesados en analizar la formación ideológica de la intimidad, los granadinos aprendían otra vez a conocer la dimensión pública de la experiencia privada de los afectos, a comprender que es posible llegar a la Historia a través de la individualidad. Pues, como bien supo ver José María Castellet, la vocación autobiográfica de sus más jóvenes antologizados en Veinte años de poesía española (1939-1959) se explicaba como una consecuencia de la "necesidad de efectuar una toma de conciencia histórica y de clase que les permit[iera] vincular su poesía con la vida cotidiana, con sus responsabilidades ciudadanas" (1960: 102). Los del cincuenta superaban, en suma, la "politización temática" del realismo socialista y evolucionaban de "un compromiso político de ideales a una crítica de tono moral y autorreflexivo" (García Montero 1993a: 201 y 102). Pero esta no era la única enseñanza: más allá del conocimiento histórico obtenido en la esfera del yo, la ejemplaridad se extendía a la búsqueda estilística que traía aparejado el ejercicio de la meditación; pues reemplazar 
la denuncia política por la reflexión moral equivalía a sustituir los acentos grandilocuentes de la épica por el tono menor de la conversación: una conquista imprescindible para quien conoce el desplazamiento de la poesía como lugar central de la cultura y las limitaciones de su alcance contra el aparato propagandístico del sistema.

Junto a la herencia fuerte del cincuenta, los poetas granadinos defendían la dignidad estética de algunos nombres canónicos de la poesía social -Celaya-Leceta, Otero, Hierrocontra el ostracismo a que los habían condenado los poetas novísimos; pero aceptaban su compañía literaria en un gesto no exento de reservas. Y ello en la conciencia de que la ideología que sustentaba el discurso de los poetas sociales era en el fondo profundamente idealista pese a su supuesta adscripción materialista o revolucionaria, en tanto no había roto con la dialéctica de las oposiciones burguesas tradicionales. Pues esta clase de literatura engagée aún distinguía, con la vieja metafísica, entre un interior puro y un exterior impuro, con lo que su revolución supuesta se limitaba únicamente a variar los contenidos, sin haber comprendido que no hay un dentro y un fuera, ya que la sustancia histórica habita en la médula del yo. Lo único que llegaba, en consecuencia, a discutirse era la cuestión del compromiso contemplado como una opción ética que conduciría coyunturalmente al Artista a descender de su lugar propio -la verdad esencial de la Poesía, la intimidad esencial del poeta al margen de la vida cotidiana- para manchar sus poemas con los contenidos espurios de la Historia, categoría de suyo separada del en sí poético (Rodríguez 2001: 286-290). De esta forma, como recuerda Luis García Montero, los poetas sociales "no rompieron con la sacralización de sus verdades internas, puras; se creyeron [...] profetas capaces de ver en su interior el camino, la buena nueva que debía servirles para capitanear la marcha histórica del pueblo" (1993b: 11). Y si la proposición del oficio poético como regenerador político todavía podía cobrar sentido en el estado de sitio de la inmediata posguerra, secuestrados los foros naturales para la discusión sobre los destinos públicos, tras el regreso de la normalidad democrática la otra sentimentalidad retrocede ante la misión positiva del poeta social: de hecho, solo ocasionalmente ha practicado una escritura de inmediato cariz político, obediente a la urgencia de coyunturas particulares, y ello en la conciencia del carácter "fronterizo" que tales ensayos poseen (García Montero, 1994).

Precisamente uno de estos ensayos, la composición "En pie de paz" de Luis García Montero (2015: 813-814), define en sus indicaciones metadiscursivas la posición ideal del autor ante una literatura de corte explícitamente político, al confrontarse con el gesto codificado de la tipología social. Ante la lógica de la violencia y la muerte, el sujeto combatiente que es también poeta se alza en pie de paz y, con claros ecos de Otero y de Celaya, no duda en abrazar la jerga retórica de la tradición socialrealista: "En pie de paz, yo vuelvo, regreso a las palabras, / a vosotras antiguas camaradas del mundo, / camaradas del hombre que os pide y os levanta / hechas lirio, consigna, empeño de futuro...”. Pero el aliento épico en que deviene el voluntarismo no tarda en desvanecerse, sin duda porque hacerse cargo de la discreta repercusión de la poesía en la conformación de la conciencia pública impide alzar el tono de la voz y acaba por determinar el acento y el mensaje de la composición: las palabras son "pequeñas como un nombre que apenas se pronuncia", 
"oídas en el sótano de las calles más tristes", "canción de retaguardia" que nada puede en la batalla de la realidad, si no es resistir -"cómplices en la noche de los enamorados"desde la barricada de la ternura. La distancia esgrimida frente a los postulados canónicos de la literatura comprometida afecta a los planteamientos ideológicos -pues esa presencia de los sentimientos íntimos refuta la consabida absolutización de la esfera pública, que no deja lugar para la individualidad-, pero no lo hace menos a los aspectos estilísticos. Los reiterados enunciados metapoéticos que sugieren la humildad de las palabras y del personaje que las profiere contestan las estrategias discursivas del realismo social, y lo hacen a través de un diálogo implícito con algunos paradigmáticos versos de Blas de Otero, autor de quien procede el título de la composición, tomado del poema "Anchas sílabas" (En castellano). La autoconciencia del sujeto que, en la composición de García Montero, se representa en el combate dialéctico con la precariedad del "náufrago que se amarra en un mástil / luchando con las olas y con su agotamiento" tiene poco que ver con el rictus mesiánico de quien ofrece su voz en el poema-prólogo de En castellano: "Aquí tenéis mi voz / alzada contra el cielo de los dioses absurdos, / mi voz apedreando las puertas de la muerte / con cantos que son duras verdades como puños" (Otero 1960: 79). Las palabras "pequeñas" y "oídas en el sótano" del poema de García Montero, su "canción de retaguardia", replican la "voz I alzada" en los versos del poeta vasco, los "cantos que son duras verdades como puños" o las palabras que apedrean, que golpean la realidad: la solemnidad retórica, en fin, el tono profético, la definición del poeta como un portavoz de verdades absolutas.

Reemplazados los acentos subidos del poeta-profeta por las maneras humildes de la persona normal, cabrá concluir que, más allá del gesto ético, la lección que la poesía social entrega a esta vertiente de la nueva poesía crítica se cińe al uso del código realista, en tanto discurso que trata de pensar la cotidianidad y de acuerdo, también, con la compartida voluntad de socialización de la poesía y la consideración del poema como espacio dialógico (Iravedra 2010b). Aunque tal vez en este punto vuelva a imperar sobre otros el poderoso ascendiente de Jaime Gil de Biedma, quien había decretado la irrenunciabilidad de ese diálogo al reclamar la consideración del lenguaje antes que nada como "un bien utilitario del patrimonio público" y el respeto por "el sentido de las palabras de la tribu" (1994: 272).

\section{Jorge RiechmanN: “Comprometerse y NO ACEPTAR COMPROMISOs”}

Desde otro lugar estético, la vocación teorizadora de Jorge Riechmann no se ha mostrado más indulgente en su evaluación del arte de compromiso en su sentido canónico, si por tal entendemos aquel cuya institucionalización dependió en primordial medida de la presión dirigista a la que la literatura quedó sometida por el marxismo ortodoxo a partir de posiciones como la de Zhdanov en el I Congreso de Escritores Soviéticos (1934). Ello es así pese a la radicalidad de la postura del autor madrileño, quien representa sin duda la expresión más vigorosa de una senda lírica que, en la última década del siglo XX, sale al paso de los códigos balsámicos de la poética de la complicidad para enarbolar sin complejos una nueva 
poesía política. La singularidad de la de Riechmann reside tanto en la apertura del abanico temático a los asuntos civiles como en la articulación de un pensamiento revolucionario impugnador de la conciencia posmoderna, que no tarda en declararse por extenso en el ensayo teórico Poesía practicable (1990): una propuesta que se nutre del ideario marxista de Manuel Sacristán y de los designios brechtianos de transformación del mundo. Desde tales presupuestos, el poeta formula su beligerancia contra las formas canónicas de la poesía de la experiencia y contra toda expresión anuente con lo estatuido; pero su reedición de los modos del compromiso le impele a hacerlo no menos contra esta categoría en su concepto más extendido y contra los postulados de la poesía social herederos de ella. De hecho, no pocos de sus textos valen para apreciar el singular trazado de fronteras que establece con esta corriente lírica. Y a tal efecto resulta indispensable el balance de encuentros y desencuentros -significativamente titulado "Comprometerse y no aceptar compromisos" - que Riechmann ofrece interpelado por Gabriel Celaya, con motivo de la recepción del premio de poesía que lleva su nombre, y que zanja como sigue: "En definitiva: lo que a quienes hemos sido etiquetados de 'nuevos poetas sociales' nos sobra de la 'vieja' poesía social es el yo heroico, con su querencia misionera, y la pretensión de hablar por los otros. Pero el trabajo de insurrección de poetas como Gabriel Celaya sigue siendo hoy tan necesario como hace treinta o cincuenta años" (2006: 68).

En efecto, por un lado, la pretensión celayana de dar voz a los vencidos es para Riechmann "el pecado original" de la poesía social, "la raíz común de sus flaquezas estéticas y éticas" (2006: 67); pues si tratar de suplantar la palabra de otros constituye una impostura moralmente inaceptable, no puede resultar estéticamente eficaz aquello que no se escribe desde el yo, según ya advertía una citadísima poética pergeñada en 1994: "Solo en la medida en que la historia colectiva haya sido vivida como experiencia personal podrá proporcionar el punto de partida para un buen poema político" (1998: 22). Por otro lado, recoger el testigo de la insurrección no es incompatible con la reiterada oposición al viejo sentido misional - "el poeta [...] tiene a lo más una tarea, pero no una misión"-y a la idea del poeta como fuente dispensadora de salvación tantas veces proclamada por Celaya: "Mientras haya en la tierra un solo hombre que cante / quedará una esperanza para todos nosotros' no son versos cerca de los cuales podamos acampar hoy" (2006: 66). No es la primera vez que Riechmann cuestiona la imagen aurática de un sujeto que se arroga facultades gnoseológicas especiales - ¿Son acaso [los poetas] profetas del superhombre?” (1990: 91)_ , previene contra un afán mesiánico que apunta rasgos de totalitarismo - "Recordemos que [...] está directamente ligado [...] con las equívocas doctrinas filosóficas del idealismo alemán" (1990: 85) - y empeña a la poesía en un cometido desmesurado; y propone, a cambio, una humildad a la altura de los seres mortales que resguarda la audacia combativa de los vuelos heroicos y los sueños redentores: "El intelectual no ha de creerse padre de la patria, héroe de la clase obrera ni redentor del mundo. Sé 'audaz, modesto y mortal", sugiere con René Char (1990: 121).

Naturalmente, socavando la imagen del sujeto sacralizado del socialrealismo se halla la relativización de la utilidad de la poesía en el orden práctico inmediato, que Riechmann 
-con otros poetas coetáneos - traslada al horizonte mediato de la ideología: no hay poema que redima el mundo, pero su poder de conmoción y su alcance ideológico contribuyen siquiera a la formación de consciencia. "Otro ritmo posible", el poema programático que clausura Poesía practicable, acota sin ingenuidad ni demagogia el alcance de la poesía como herramienta de intervención:

Un buen verso
no sacia el hambre.

Un buen verso

no construye un jardín.

Un buen verso

no derriba al tirano.

Un verso

en el mejor de los casos consigue

cortarte la respiración

(la digestión casi nunca)

y su ritmo insinúa otro ritmo posible

para tu sangre y para los planetas (Riechmann 1990: 179).

Si estos versos contestan implícitamente los enunciados utópicos de la poesía social, no faltan los que proceden a su abierta desmitificación por vía irónica y paródica, tal como sucede en "Tráfico de armas" a propósito del célebre dictum celayano que da título a un poema de Cantos iberos y — casi- a este trabajo:

¿La poesía es un arma

de futuro cargada?

A lo mejor gastó

mucha pólvora en salvas.

A lo mejor el tiro salió por la culata.

[...]

Quizá solo la risa

puede rasgar la máscara,

puede quebrar las armas (Riechmann 1990: 166).

Más allá de su determinación pacifista, el texto traslada la conciencia de que las luchas sociales se dirimen en el mundo real mucho antes que en el escenario del poema. Y ello es congruente con la resistencia de Riechmann a cualquier servidumbre a instancias externas 
- “La poesía no debe ser sierva nunca” (1998: 91) - y la reivindicación de la autonomía (que no autarquía) radical del género como una conquista irrenunciable de la modernidad. Por ello, en consonancia con las conclusiones de la otra sentimentalidad, que decretaban como falsa la clásica polémica entre esteticismo (o pureza) y compromiso, y todavía a instancias de las interpelaciones celayanas, Riechmann impugna la dialéctica entre belleza incontaminada y palabra instrumental que se reproduce en los poetas sociales, teóricamente dispuestos a la inmolación de la belleza:

"Sabed que la belleza, eso que llaman / cielo, mínima flor, Mar Amarillo / ya lo he visto. No tengo tiempo. Antes / hay que poner los hombres en su sitio" (Blas de Otero).

¿Poner los hombres, o poner los nombres en su sitio? ¿Por qué hay que pensar que una de las dos tareas tiene preferencia sobre la otra... o que se trata de tareas distintas? [...] [René Char] acaba el más impresionante de los documentos poéticos de la resistencia al nazismo, Hojas de Hipnos, con la anotación siguiente: "En nuestras tinieblas no hay un sitio para la Belleza. Todo el sitio es para la Belleza." En este caso, el poeta provenzal tiene razón frente al bilbaíno (Riechmann 2006: 72).

De hecho, la reserva ante la subordinación instrumental de la poesía desata en Jorge Riechmann la necesidad de precisar su adscripción a cualquier especie de compromiso artístico en su sentido clásico y aun de redefinir el término; pues el compromiso que este asume -siendo sinónimo de responsabilidad- limita con la rigurosa independencia y se sitúa en la fidelidad a lo real. "Sobre el lugar del poeta en la ciudad democrática" es un texto imprescindible para conocer las cautelas que el concepto le suscita:

Compromiso, en un primer sentido, puede denotar sumisión a una instancia ideológica exterior [...]; en un segundo sentido denota el esfuerzo por que la palabra tenga consecuencias fuera del orden del discurso [...]. En la primera acepción, "descompromiso" es sinónimo de independencia; en la segunda, de irresponsabilidad.

Por eso mismo, la expresión “poesía comprometida” es también equívoca [...]. Según ha señalado Cristoph Hein, rebelándose contra el compromiso en cuanto sumisión a control externo, una virtud esencial de la poesía es su incapacidad para el compromiso: no sirve para chalaneos ni claudicaciones.

Su extremada radicalidad se deriva de una extremada fidelidad a lo real y a las posibilidades de lo real. En muchas situaciones, la palabra fidelidad me parece más libre de equívocos que la palabra compromiso (Riechmann 1998: 126-127).

En buena lógica, esta exigencia de autonomía (tanto como la conciencia de la sutil intervención política del género) emancipa la creación de las históricas restricciones 
formales a que el poeta se obligaba para brindar, a cambio, una holgada libertad de ejecución. Ello permite comprender que Jorge Riechmann solicite un lugar en el canon del compromiso para la aventura surrealista, expulsada de él por la ortodoxia marxista y que sin embargo considera, con la estética del material nucleada por Brecht, uno de los dos sucesos estéticos más importantes del siglo XX. De ambos, el poeta destaca el común intento de liberar al arte de su condición de "parásito de la realidad" y de superar la estética de la representación -ya sea por la vía de una estética de la producción (en el grupo de Brecht) o por la de una estética de lo maravilloso (en el de Breton)- (1990: 87). Y el hecho es que este postulado apuntala hoy la tarea artística de Riechmann, en congruencia con un giro teórico que le ha conducido a relegar a un lugar secundario la función comunicativa del texto, uno de los principios nucleares del socialrealismo poético defendido también en sus inicios como una categoría primordial: "La guerrilla comunicativa -piensa ahora en cambio- puede ser ciertamente una estrategia poética, pero solo una entre otras (el poema no es necesariamente 'comunicación')" (2003: 260). Y ya no es solo que, en sintonía con los poetas críticos de los años sesenta, que clamaron por la dignificación del género poniendo de relieve su compromiso gnoseológico, Riechmann privilegie la tarea indagadora; además, y contraviniendo al Gil de Biedma que exigía a los poemas el "mínimo de sentido" de una carta comercial (1994: 272), el poeta no duda en subvertir ese sentido en beneficio de una inquisición que aconseja separarse del lenguaje convenido y, según cree, invalidado para la revelación del mundo. Más aún, la transigencia con el hermetismo se acompaña de una relectura verdaderamente llamativa del retiro en las otrora denostadas torres marfileńas, según prueba el asentimiento del poeta a las consideraciones de Manuel Sacristán sobre el arte de Joan Brossa:

No estoy muy convencido de que los "aires herméticos" excluyan la eficacia política. [...] Brossa puede parecer el tipo de intelectual situado en su "torre de marfil". Lo que él, como otros, intenta comprar con el encierro en esa torre es la ruptura más o menos lograda con la cultura dominante, que es -incluso en el pueblo- la cultura de las clases dominantes. [...] El aislamiento de la poesía -y del teatro- de Brossa [...] es una recusación mucho más completa de esta sociedad que el vociferar inocente o intencionado de algunos intelectuales muy comunicativos que actúan como agentes publicitarios del gremio (Cit. en Riechmann 2003: 175-176).

Si Riechmann se aproxima en este punto al García Montero que conceptuaba a Juan Ramón como un poeta "puro por compromiso" (2003: 13) — defendiendo la militancia social de quien, desengañado de una política corrupta, elegía el rigor del trabajo privado como fórmula de contribución al regeneracionismo cívico-, sobre todo sintoniza con los poetas valencianos del desaparecido Colectivo Alicia Bajo Cero; pues, como él, estos reclaman la apertura del canon del compromiso a los registros vanguardistas, que, si se alejan de las fórmulas más ortodoxas en que han venido a encauzarse las voluntades cívicas, han demostrado su resistencia histórica a ser asimilados como lenguajes de poder. 


\section{Alicia Bajo Cero o la insurrección de la vanguardia}

En efecto, los poetas nucleados en torno a la Unión de Escritores del País Valenciano y, más en concreto, quienes durante un tiempo se ocultaron bajo el nombre de Alicia Bajo Cero, han expresado su discrepancia de las tradicionales modulaciones de nuestra poesía comprometida, sobre todo en nombre de una negación del contenido como clave de la insurrección congruente con su denuncia de las trampas de la representación y del espejismo de la transparencia. Son convicciones en las que desembocan desde una indagación crítica en la realidad inseparable de la investigación de un discurso irreductible a los sistemas representativos del poder. Pues "no seguir hablando el lenguaje del poder", un enunciado de Jorge Riechmann que han adoptado como lema condensador de su programa (Colectivo 1997: 20), pasa según sus cálculos por resistirse a concebir el lenguaje como un mero instrumento transparente al servicio de la comunicación de significados estables. Ello exige la habilitación de procedimientos desautomatizadores de la lengua social, el recurso a la elipsis, al fragmento y a lo inacabado, que no solo atestiguarían mejor la catástrofe histórica de un mundo hecho pedazos, sino que promoverían la intervención crítica de un lector que la propaganda institucional quiere pasivo y desmemoriado.

La radicalización de este programa conduce a algunos autores del colectivo valenciano, como Antonio Méndez Rubio, a construir su territorio poético en las afueras de la referencialidad. Y desde tal lugar estético, puede comprenderse que este creador y teórico de la literatura haya cuestionado los planteamientos sobre poética y política operantes en los principales estudios sobre el compromiso poético español del pasado siglo, con repercusiones decisivas en la propuesta canónica resultante. Sobre todo, Méndez Rubio revisa el enfoque de Lechner en su clásico libro sobre El compromiso en la poesía española del siglo XX (1968), para llamar la atención sobre uno de los supuestos centrales que el autor pone en juego como precondición del compromiso - "el principio de realidad como eje" del poema que debe reflejar la experiencia social-y alertar sobre el "régimen de exclusiones" que tal precondición ha generado. Pues, en efecto, el modelo de compromiso defendido afecta cuando menos al descrédito en bloque del arte de vanguardia o no figurativo, y proyecta toda una zona de sombra sobre amplias parcelas de la poesía española contemporánea que, desde un enfoque menos tradicionalista, habrían arrojado una luz distinta sobre la categoría considerada. Una inercia semejante denuncia el teórico en el célebre trabajo de Cano Ballesta La poesía española entre pureza y revolución (1930-1936) (1972), que recupera el debate sobre poesía y política "sobre la base del ensalzamiento del realismo crítico y la acusación de esteticismo y deshumanización [...] sobre toda huella de vanguardia”; así como en la antología preparada por Leopoldo de Luis con el título de Poesía social (1965, 1968), donde el autor imputa a poéticas como la surrealista el incurrir en "fórmulas evasivas" e "idealistas", aunque una mayor amplitud de miras le permita integrar en su muestra a algunos poetas "descontentos con la inercia realista y con la ecuación que venía identificando esta opción estética con la crítica política (ante todo temática) durante el siglo XX” (Méndez Rubio 2007). 
Precisamente han de ser estos poetas tenidos como sociales -incluso como poetas sociales canónicos, al menos en tanto que propuestos en la canonizadora antología- y excepcionalmente refractarios a esa primacía del principio de realidad los que conciten la alabanza de Antonio Méndez Rubio: así, el Gabino-Alejandro Carriedo que propone la búsqueda de lenguajes en expansión (Luis 2000: 386) o, sobre todo, el Ángel Crespo que subraya el contrasentido de pretender "un cambio de las circunstancias sociales con una técnica conformista” (Luis 2000: 414). En congruencia con este argumento, se comprende asimismo que Méndez Rubio contemple la "voluntad ingenua de entrar en conflicto con la realidad dominante en su propio terreno" como el principal límite de una poesía crítica de corte realista - la que hasta aquí ha conformado el canon del compromiso- "que no puede oponerse al orden establecido sin aceptar las condiciones de partida impuestas por su lenguaje" (2002: 44). Pues no se olvide que para el beligerante colectivo en el que ha militado Méndez Rubio, heredero de la teoría estética de Adorno, una poesía crítica dudosamente puede articularse sin una puesta en crisis del lenguaje que media en las relaciones sociales de dominio. Por ello el poeta reivindica la apertura del canon del compromiso no solo a los discursos de vanguardia, sino también a un anarquismo libertario en el que la denuncia explícita es solo la punta del iceberg de una poesía donde el enunciado importa menos que la enunciación o la práctica, una práctica que enriquece -y no solo testimonia- el tiempo en que se inscribe.

Desde esta perspectiva resulta lógico que, en el terreno de la teoría crítica, Méndez Rubio cuestione el "marxismo mecanicista y dogmático" que concibe la escritura como producto de la realidad, una idea subsidiaria del absolutismo del reflejo que ha alimentado las distintas formas del realismo socialista y a nuestra poesía social; y defienda, a cambio, un concepto de lenguaje, reprimido por el comunismo estalinista y planteado por un marxismo heterodoxo (Voloshinov), como parte constitutiva de la realidad, susceptible en consecuencia de transformarla, pues, mediante la articulación de estrategias de refracción y desvío, diseña un marco nuevo de enunciación capaz de alterar las reglas del juego. En absoluto sorprende que esta clase de enfoque haya conducido al poeta y teórico a solicitar el ingreso en el canon del compromiso de los supuestamente descomprometidos poetas novísimos (Jenaro Talens, José-Miguel Ullán, Leopoldo María Panero...), que desplazaron la insurrección desde el mensaje o el enunciado hacia el ejercicio desenmascarador de la función metapoética y la crítica del lenguaje (Méndez Rubio 2004).

Contra las inercias del canon en la tradición peninsular y, en concreto, contra algunos prejuicios bien asentados a la hora de pensar una poesía de designio crítico se revuelve asimismo Enrique Falcón, otro nombre capital del colectivo valenciano cuyo proyecto poético pasa también por desquiciar, mediante el descontrol y el desvío lingüístico, la continuidad de la lengua social, como forma de poner en crisis una concepción dogmática de la realidad o del significado. Naturalmente, Falcón impugna de nuevo el mito de la transparencia o el prejuicio de la representación; pero, aunque con menos arreos teóricos que su correligionario, el poeta convoca asimismo, para rebatirlos, otras ideas o presupuestos que flotan en el inconsciente colectivo a resultas de su afianzamiento por las prácticas críticas más 
unánimemente reconocidas como tales: a) esta clase de poesía es "ajena a lo íntimo (sic) a causa de su voluntad colectiva"; b) "ha de estar dirigida a los pobres (sic)"; c) "ha de perseguir un cambio significativo (sic) en las estructuras sociales y políticas de su tiempo" (Falcón 2006: 133-145). Respecto a la presunción primera, Falcón contesta la separación de lo privado y lo público heredada de la tradición racionalista burguesa y todavía operante en el paradigma social; aunque, contra lo que pudiera esperarse, no reconocemos en el discurso del poeta la interiorización de las lecciones del marxismo de Althusser que enseñaron, en cambio, a la otra sentimentalidad a pensar la intimidad como una instancia histórica; por el contrario, sin remover de raíz la dicotomía impugnada, al valenciano le basta solicitar el derecho a que los desvelos de un sujeto con inquietudes civiles sean considerados materia personal: "Mientras nuestra suerte común no sea entendida como un asunto también personal, no cabrá un lugar para la esperanza" (2006: 135)ํ. En cuanto a la segunda premisa, Falcón refuta en el fondo el utópico postulado oteriano de "la inmensa mayoría", y más directamente, su reformulación en otro aserto no menos ilusorio del Celaya de Cantos iberos: "Poesía para el pobre, poesía necesaria / como el pan de cada día". Y a rebajar el componente utópico de la poesía social se encamina asimismo la recusación del tercer presupuesto; ya que, lejos de perseguir cambios estructurales -tarea reservada a la acción del poeta en calidad de ciudadano-, el poema aspira a cumplirse en su efecto desenmascarador; de ahí que se convoquen unas palabras de Hauser que ya presidían Poesía y poder (1997), ensayo teórico firmado por Alicia Bajo Cero: "El criterio de fecundidad de un arte comprometido no estriba en la solución de crisis y conflictos, sino en combatir la ilusión de que -en medio de los peligros y bajo el signo de la catástrofe- todavía se sigue viviendo en un mundo sin peligro alguno" (2006: 144). La afirmación de la "inutilidad" de la poesía política en que al fin viene a parar el discurso de Falcón aspira, en última instancia, a detener un nuevo apriorismo sacralizador de las producciones culturales, también alentado por la poética social: la supuesta condición salvífica de la escritura, necesariamente rebatida por quien propugna la desmitificación de la instancia del autor y de la figura del poeta, que no ha de ser encumbrado ni como sujeto capitalizador de la belleza ni como fuente de redención histórica.

\section{El REALISMO SUCIO: UN COMPROMISO MALGRÉ LUI}

Más problemático resulta definir la brecha que separa a la trinchera lírica del realismo sucio del canon poético del compromiso, ya que esta etiqueta aglutinadora no designa una entidad compacta, ni por lo que se refiere a su modelo retórico ni al emplazamiento que elige su sujeto, en un lugar inestable entre el cinismo y la consternación. No hay duda, ahora bien, de que esta fórmula importada del mundo anglosajón, que acoge las relaciones

\footnotetext{
$1 \quad$ Valga decir en descargo del poeta que aquello que no acaba de resolver en la teoría lo consuma de hecho en la práctica, al diseñar un sujeto alterado que -sin borrar su identidad en minúscula: enrique- se propone como lugar de confluencia de voces.
} 
problemáticas del hombre contemporáneo con el nuevo espacio urbano, atendiendo a sus parcelas menos complacientes, incorpora un componente crítico que no se ve mermado por la supuesta neutralidad documental ni por la ausencia de sesgo programático de la voz enunciadora; antes al contrario, el testimonio descarnado de los sucesos diarios, acaecidos en un horizonte urbano convertido en trasunto de la orfandad del sujeto en una sociedad terminal, tiende a promover un compromiso malgré lui. $\mathrm{Y}$ he aquí su singularidad, puesto que la generalizada renuencia no solo a articular un proyecto de salvación colectiva, sino a la menor implicación en una ética de orden constructivo, diseña una voz lírica que difiere sin ambages del sujeto heroico del realismo social. La condición desengañada y displicente -aderezada con destellos de malditismo- de este personaje que habita en el exasperado nihilismo o en los aledańos de la marginalidad, abdica de cualquier esperanza y opone una lucidez desolada o cínica a la vocación profética de la retórica obrerista, promoviendo la desmitificación paródica de los consabidos lemas programáticos. De hecho, una nueva "Glosa a Celaya" y a su célebre aserto - "La poesía es un arma cargada de futuro"-, a cargo en este caso de Roger Wolfe (2008: 262), establece tal vez la temperatura exacta de este nuevo compromiso posmoderno; pues el colofón irónico - "Y el futuro / es del Banco / de Santander"- sella el poema con una proclamación terminante de la falta de expectativas sociales en la era del capitalismo avanzado y contesta la demagogia de la poesía social.

No obstante, y aunque tal actitud identifique paradigmáticamente la tendencia, la adhesión al canon del compromiso entre los cultivadores de este realismo destemplado es tan diversa como las propias voces que lo informan. La radicalidad escéptica del personaje de Roger Wolfe (que encarna la postura más cercana al referente anglosajón), tanto como un pensamiento iconoclasta y refractario a los modelos morales sancionados, determinan la ambigüedad del autor respecto de la noción de compromiso. Tal parece inferirse de un texto así titulado, "Compromiso" (Wolfe 2008: 165), que si de entrada quisiera zanjar la relación del hablante con esta categoría en la displicencia del epígrafe inicial -“-iEres político, Lou? I - ¿Político? ¿Con respecto a qué? Dame un tema, I te daré un pañuelo, y me limpias el culo con él..."-, acaba formulando una denuncia del tan pretencioso como inoperante voluntarismo de sus colegas, en su afán de implicarse en otra realidad distinta de la pegada a la piel del sujeto que escribe:
Hay escritores
que se empeñan
en que los libros
siempre están
en otra parte.
[...]
cualquier
jodida parte
menos donde ellos
estén. 
En el fondo, ni el escepticismo ni el exhibicionismo displicente han de confundirse con la indiferencia cuando una poderosa rebeldía apelativa promueve el riguroso enjuiciamiento de una realidad sin exclusiones: "toda esa poesía que no cabe en un poema" (Wolfe 2008: 231). Solo que, antes que con la vocación de combatiente del Machado de la guerra, que buscaba en su gramática de urgencia la eficacia del pistolón de Líster ("Si mi pluma valiera tu pistola / de capitán, contento moriría"), Roger Wolfe se identifica con el compromiso reflexivo y dialógico de Juan de Mairena; y si refuta al primero en su "Poética negra" - "Una pluma sigue siendo preferible / a tener que desempolvar / la mágnum 44"(2008: 69), la célebre máxima del segundo abriga sintomáticamente la poesía reunida del británico: "La poesía es el diálogo de un hombre con su tiempo".

No ha sido menos debatida la dimensión crítica de la poesía de Manuel Vilas, pese a su elaboración de un discurso que se afirma político y proclama una ambición de desenmascaramiento ideológico (Vilas 2010: 8). Sin embargo, la urdimbre espiritual de la poesía de Vilas se construye ambiguamente a partir de un desconcertante maridaje de posicionamientos discursivos -entre la celebración y la denuncia, la rebeldía y el cinismo, el envilecimiento y la piedad- que conspira contra cualquier proyección estable de la realidad y del sujeto que la enuncia. Aquí reside, ahora bien, su más potente munición perturbadora; ya que ese alegato paradójico, proferido desde una comprensiva declaración de amor -al dinero, a los coches, a la prostitución, a los McDonald's- emparentada con el vitalismo nietzscheano, contiene un designio quebrantador de la disciplina pequeño-burguesa, busca invertir la normalidad del pensamiento y enfrenta al lector con sus propias fronteras morales. He ahí la radicalidad política de esta escritura, que tan enfáticamente reclama el autor aunque, a la postre, su deseo de "no contribuir al orden moral de este mundo" (Vilas 2010: 11) se halle a punto de sabotear a cada paso una lectura en clave ética de su reflexión histórica. Pese a que lo que resulta de hecho boicoteado es el maniqueísmo y cualquier posibilidad moralizante, cuidadosamente bordeados por un poeta cuya indignación cívica -que huye una vez más de los imperativos de la corrección- no es incompatible con el implícito rechazo de los códigos de la lírica social.

Si la displicencia programática de Roger Wolfe (que cede la palabra a un sujeto retadoramente insolidario) o el exaltado vitalismo de Manuel Vilas (que asiente ambiguamente a la filosofía posmoderna o cruza la línea del envilecimiento moral) deliberadamente comprometen su adscripción a una poesía crítica, el personaje marginal de David González abandona, en cambio, ocasionalmente la indolencia para reproducir las consignas del discurso revolucionario tradicional: "No digas que No. / Sí puedes cambiar el mundo" (2009: 250). En tales casos, la equivocidad moral que identifica al realismo sucio, solidaria con la orfandad de creencias del sujeto contemporáneo y con el desencanto político de los tiempos, excepcionalmente desemboca en una resuelta disposición combativa, y en una militancia cívica que reconcilia la oblicuidad de la tendencia con la denuncia directa del compromiso canónico. 


\section{Las Voces del EXtremo y el terrorismo cultural}

Son seguramente los llamados "poetas de la conciencia", vinculados al colectivo onubense Voces del Extremo y capitaneados por Antonio Orihuela, quienes se hallan más cercanos a las formas canónicas del compromiso poético. Pues este grupo, que dice encarar el ejercicio creativo como una actuación estrictamente política orientada a la crítica del neoliberalismo, hereda de las poéticas sociales de treinta años atrás tanto la razón fedataria y la denuncia incisiva como una palabra narrativa de extraordinaria claridad referencial, rayana en el prosaísmo, garante de una eficacia comunicativa entendida, igual que entonces, como potencia revolucionaria. La novedad, sin embargo, reside en un componente de provocación solidario con una concepción de la escritura como "acto de terrorismo cultural" (Bagué Quílez 2006: 161), que funda su carácter transgresor en el cultivo de una poesía fronteriza o decididamente antipoética. En tal sentido, la erosión ideológica de la poesía de la conciencia ya no se confía únicamente a la carga crítica de los significados o a la virulencia del mensaje, sino también a la fuerza delictiva de un vehículo lingüístico impertinente y estéticamente anárquico, que busca irritar al lector mediante el desconcierto de expectativas, la deliberada ausencia de concesiones al buen gusto y el quebrantamiento de los usos de la tradición.

El relativo concierto con las pautas retóricas clásicas que -pese a su evidente giro prosaico- aún ostenta el convencional modelo lingüístico de los compromisos poéticos en Espańa no será, aun así, un argumento esgrimido por el colectivo onubense para ilustrar su distancia de estos. A cambio, la radicalidad política con que enfrentan la tarea artística las Voces del Extremo no es incompatible con su deseo de relativización, sugerido en un explícito diálogo no exento de reservas, de algunos celebrados axiomas de la poesía social. Así, por ejemplo, Eladio Orta, uno de los componentes más activos de este núcleo lírico, reescribe una vez más el popular aserto de Celaya: "La poesía -reza uno de sus títulos- es un arma brutal" (Correyero 1998: 187); con lo que no solo proclama la buscada virulencia de un discurso terrorista que aspira a remover los cimientos del lector y dinamitar lo estatuido, sino que corrige de camino, por vía de parodia, las proyecciones utópicas del optimismo celayano y los enunciados del compromiso de posguerra. Por su parte, y asimismo para refutar-desde un sombrío sarcasmo- la euforia del precedente vasco, Antonio Orihuela convoca en uno de sus textos otro de los lemas más glosados del mismo poema de Cantos iberos: "[Esto] Tampoco es '...poesía necesaria, poesía para el pobre...' / Los pobres están demasiado ocupados / trabajando para que los burgueses / puedan escribir poesía" (Correyero 1998: 240).

No obstante, el ideario que anima tales réplicas no siempre es coherente con la praxis ni con otras convicciones abrazadas. En el contexto del poema que acaba de citarse, "Ya hay quien, como amigo", la glosa de Orihuela se halla destinada a contestar la concepción extraordinaria del hablante como fuente redentora, a recusar, en suma, la sacralización de la figura del Poeta para presentarlo como semejante y hermano del lector, un sujeto consciente del alcance real de su escritura. Este apunte escéptico, ahora bien, no concuerda con el sacrificio de la estética en aras de la urgencia cívica -contra el que más 
atrás veíamos revolverse a Jorge Riechmann- reiteradamente promulgado por estos autores; ya que la conciencia del lugar exacto del poeta en el discurso de la realidad debería liberar la creación de las antiguas ataduras formales que atenazaron a aquel poeta del pueblo ilusionado con redimirlo. Sin embargo, Eladio Orta, en otro de sus poemas programáticos, se reconoce "rompiendo versos / a pedazos / escribiendo mal a conciencia, / porque bien otros ya lo hacen / y no ha ocurrido nada" (Correyero 1998: 261): esto es, reeditando otro archicitado aserto de Celaya-Leceta - "escribiría un poema perfecto / si no fuera indecente hacerlo en estos tiempos" (Tranquilamente hablando)-, expresa su renuncia a la belleza estética en aras de un compromiso ético que elige el feísmo elocutivo como mecanismo revulsivo o desenmascarador. No son otros los planteamientos que conducen a Antonio Orihuela a legitimar la naturaleza antipoética (incluso, no poética) de un discurso lírico que subordina los requerimientos formales al imperativo moral de desvelar la verdadera realidad: "Puede que mi poesía ya no sea poesía, / porque llega un momento en el que ya no se puede seguir siendo / por más tiempo un cómplice, silencioso, / de lo que R E A L M E N T E pasa” (Correyero 1998: 241).

$\mathrm{Y}$ el hecho es que, en los casos menos acertados, este sacrificio de la "poeticidad socializada" (Sánchez Torre 2002: 51) configura un discurso que adolece de laxitud imaginativa o de una inconveniente simplificación estilística: por "olvidar las oscuras golondrinas" y "llamar a las cosas por su nombre", según escribe Muñoz Álvarez (VV. AA. 1999: 16), ocasionalmente nos hallamos ante una poesía a punto de precipitarse hacia la prosa, no tanto por su prosaísmo expresivo como por la univocidad de su mensaje, más cerca del artículo de opinión que del poema. En sus momentos más desafortunados, los resultados de las Voces del Extremo se resienten -por mucho que contesten sus premisas- de la desvitalización lingüística en que incurrió el socialrealismo más epigonal.

\section{CoDA}

Vale lo antedicho como muestra de que las reiteradas reservas y la desafección expresada por los nuevos autores hacia sus precedentes canónicos y, con particular insistencia, hacia su antecedente mediato en la posguerra, sugieren un hiato que no siempre concuerda con el grado real de parentesco. Y es que los elementales principios todavía compartidos a menudo promueven -recuperando la reflexión de Sánchez Torre citada al inicio- no solo "actitudes" análogas, sino también "concreciones discursivas" que, pese a las constatadas resistencias al canon, no ocultan sus deudas con él ${ }^{2}$. Más aún cuando -no debe olvidarse-

\footnotetext{
2 Ha de quedar para otro lugar la argumentación de este aserto. Pero valga siquiera apuntar que, de modo más que ocasional, el Jorge Riechmann que ha formulado su rechazo a una clase de poesía concebida como vehículo de mensajes ideológicos (pues la disposición del poeta no es la del que sabe y comunica, sino la del que no sabe y va a aprender [1998: 174]), no solo cede a una práctica poética que "vehicula rebeliones o critica lo inaceptable" (2006: 132); sino que, acogido al gramsciano optimismo de la voluntad, propugna una ambición transformadora en la que hallan sentido los imperativos movilizadores del discurso de la revolución -"Dos
} 
los escollos en que tropiezan las ejecuciones menos felices del realismo social de los ańos cincuenta no tardan en ser superados por el realismo crítico de los sesenta, en manos del cual la tendencia pierde su candidez primera para asumir formas más complejas que, en algunos de sus rasgos (predominio del componente individual, ironía desacralizadora, tono menor del discurso...), conservan plena vigencia en la poesía de hoy mismo. Es un dato que nos avisa de que, como también advertía Sánchez Torre (2002: 49), no conviene contemplar como un todo lo que una lectura ni siquiera demasiado sagaz de inmediato revela como una realidad multiforme.

Dicho esto, qué duda cabe de que la reciente poesía cívica, hija de su tiempo cultural e histórico, ha habilitado maneras de pensar y escribir el compromiso a la altura de las nuevas circunstancias. Superado el desorden impuesto por la dictadura franquista, la restitución de las libertades públicas y los cauces de la normalidad democrática han obligado al poeta a redefinir su papel como árbitro moral de una sociedad que, hasta entonces, había reclamado su activa militancia, llamado como estaba a proponer unas condiciones de vida que no se hallaban al alcance de la batalla política. A su vez, el desfondamiento ideológico de los tiempos, concordante con la respiración escéptica y nihilista de una posmodernidad asentada en un desierto de creencias, ha venido a promover un compromiso en tono menor no solo refractario al absolutismo de los dogmas y a cualquier apriorismo, sino asimismo muy consciente del alcance de sus fuerzas en el pulso del presente. Si todo ello ha desatado las consabidas enmiendas al canon y las relecturas resultantes, no ha impedido al mismo tiempo que, sin esperanza, con convencimiento, o con esa esperanza vestigial congruente con los valores provisionales de la cultura posmoderna, un puñado de artistas renuentes al encogimiento de hombros solicite a la poesía la construcción de una conciencia crítica, desprovista de afanes redentoristas, que a su vez solo es posible a partir de la habilitación de un nuevo lenguaje. Con independencia de las distintas caligrafías pergeñadas, la precariedad espiritual del momento dicta la común temperatura moral con que se encara la tarea, felizmente capturada, según creo, en un enunciado de Jorge Riechmann al que todos podrían acogerse: "Entre la resignación a la impotencia y las fantasías de omnipotencia, un difícil espacio donde lo real dialoga con lo posible, mientras tú vas aprendiendo a orientarte" (1998: 13).

manos enlazadas / cambian el mundo" (2011: 473) - y la esperanza queda dicha como estrategia psíquica para la lucha, reproduciendo una reconocible convención de la retórica social. Aunque harto más excepcionalmente, la politización temática rechazada por la otra sentimentalidad aflora en los poemas de Luis García Montero, cuyos versos no siempre se detienen en la investigación ideológica del yo, sino que, atentos a las urgencias del presente, verbalizan un contenido político o se entregan al testimonio y la denuncia directa: "El agua moja hoy / los pies de los que viven con los ojos cerrados, / las tarjetas de crédito que miran a otra parte, / [...] / la paz del que prefiere no saber, / ni preguntar, ni preguntarse" (2015: 633). Por su parte, los valedores de un compromiso de vanguardia no deberían menospreciar, como precedente bien asentado, la vertiente alucinada de la poesía de José Hierro, por más que no hayan sido seguramente sus alucinaciones tanto como sus reportajes -hasta donde ambas categorías pueden disociarse- las que le han procurado un lugar indiscutido en la terna canónica (CelayaOtero-Hierro) de la poesía social. 


\section{OBRAS CITADAS}

Bagué Quílez, Luis. 2006. Poesía en pie de paz. Modos del compromiso hacia el tercer milenio. Valencia: Pre-Textos.

Bloom, Harold. 1994. The Western Canon. The Books and School of the Ages. New York: Harcourt Brace.

Cano Ballesta, Juan. 1972. La poesía española entre pureza y revolución (1930-1936). Biblioteca Románica Hispánica. Madrid: Gredos.

Castellet, José María (ed.). 1960. Veinte años de poesía española (1939-1959). Barcelona: Seix Barral.

Colectivo Alicia Bajo Cero. 1997. Poesía y poder. Valencia: Ediciones Bajo Cero.

Correyero, Isla (ed.). 1998. Feroces. Radicales, marginales y heterodoxos en la última poesía española. Barcelona: DVD.

Díaz de Castro, Francisco. 2003. La otra sentimentalidad. Estudio y antología. Sevilla: Fundación José Manuel Lara.

Falcón, Enrique. 2006. "Cuatro tesis de mayo". Escrituras del desconcierto. El imaginario creativo del siglo XXI. Virgilio Tortosa (ed.). Alicante: Universidad. 133-145.

García Montero, Luis. 1993a. Confesiones poéticas. Maillot Amarillo. Granada: Diputación. . 1993b. El realismo singular. Bilbao: Instituto Vasco de las Artes y las Letras. . 1994. "Trazado de fronteras". Además. Madrid: Hiperión. 9-21. . 2003. "Poetas políticos y ejecutivos bohemios". Hace falta estar ciego. Poéticas del compromiso para el siglo XXI. José M. Mariscal y Carlos Pardo (eds.). Madrid: Visor. 11-23.

. 2006. Los dueños del vacío. La conciencia poética, entre la identidad y los vínculos. Marginales. Barcelona: Tusquets. . 2015. Poesía completa (1980-2015). Marginales. Barcelona: Tusquets.

Gil de Biedma, Jaime. 1994. El pie de la letra. Ensayos completos. Barcelona: Crítica.

González, David. 2009. El amor ya no es contemporáneo. El amor sigue sin ser contemporáneo. Tenerife: Baile del Sol.

Iravedra, Araceli. 2010a. El compromiso después del compromiso. Poesía, democracia y globalización (poéticas 1980-2005). Arte y Humanidades. Madrid: UNED. . 2010b. "Trazado de fronteras: con y contra Blas de Otero". Compromisos y palabras bajo el franquismo. Recordando a Blas de Otero (1979-2009). Araceli Iravedra y Leopoldo Sánchez Torre (eds.). Sevilla: Renacimiento. 319-334.

. 2013. “Después de este desorden impuesto’ o las voces del posfranquismo. (El canon del compromiso y el compromiso con el canon)". Políticas poéticas. De canon y compromiso en la poesía española del siglo XX. Araceli Iravedra (ed.). Madrid: Iberoamericana; Vervuert. 203-255.

Lechner, J. 2004. El compromiso en la poesía española del siglo XX. 1968. Alicante: Universidad.

Luis, Leopoldo de (ed). 2000. Poesía social española contemporánea. Antología (1939-1968). 
Poesía social. 1965, 1968. Fanny Rubio y Jorge Urrutia (eds.). Clásicos de Biblioteca Nueva. Madrid: Biblioteca Nueva.

Machado, Antonio. 1989. Poesía y prosa. Oreste Macrí (ed.). Vols. 3-4. Madrid: Espasa Calpe; Fundación Antonio Machado. 4 vols.

Mainer, José-Carlos. 1998. "Sobre el canon de la literatura española del siglo XX". El canon literario. Enric Sullà (ed.). Bibliotheca Philologica. Madrid: Arco/Libros. 271-299.

Méndez Rubio, Antonio. 2002. "Otra poesía es posible. La cuestión del sujeto y la crítica social en la poesía reciente”. Ínsula 671-672: 42-44.

. 2004. Poesía '68. Para una historia imposible: escritura y sociedad 1968-1978. Documentos para la Historia de la Poesía Española del Siglo XX. Madrid: Biblioteca Nueva.

. 2007. "El canon del compromiso". Prosopopeya [Universitat de València] 5: 209230.

Otero, Blas de. 1960. Con la inmensa mayoría. Buenos Aires: Losada.

Riechmann, Jorge. 1990. Poesía practicable. Madrid: Hiperión. . 1998. Canciones allende lo humano. Dicho y Hecho. Madrid: Hiperión. 2003. Una morada en el aire. Barcelona: El Viejo Topo. . 2006. Resistencia de materiales. Ensayos sobre el mundo y la poesía y el mundo (19982004). Barcelona: Montesinos. 2011. Futuralgia. Poesía reunida 1979-2000. Madrid: Calambur.

Rodríguez, Juan Carlos. 1999. Dichos y escritos. Sobre "La otra sentimentalidad" y otros textos fechados de poética. Madrid: Hiperión. 2001. La norma literaria. Ensayo Literario. Barcelona: Debate. . 2003. "La poesía política de Alberti". Hace falta estar ciego. Poéticas del compromiso para el siglo XXI. José M. Mariscal y Carlos Pardo (eds.). Madrid: Visor. 101-127.

Sánchez Torre, Leopoldo. 2002. "De lo real y sus retóricas: realismo y antipoesía en las nuevas poéticas del compromiso". Insula 671-672: 49-53.

Soria Olmedo, Andrés y Rafael Alberti. 1991. Discursos pronunciados en el acto de investidura de Doctor "Honoris Causa" de don Rafael Alberti. Granada: Universidad.

Talens, Jenaro. 2000. El sujeto vacío. Cultura y poesía en territorio Babel. Frónesis. Madrid: Cátedra; Universitat de València.

Vilas, Manuel. 2010. Amor. Poesía reunida, 1988-2010. Madrid: Visor.

VV. AA. 1999. Voces del Extremo. Las voces de la poesía española al otro extremo de la centuria. Moguer: Fundación Juan Ramón Jiménez.

Wolfe, Roger. 2008. Noches de blanco papel. Poesía completa 1986-2001. Barcelona: Huacanamo. 
